\title{
Method for Saving Energy Battery Based in Context for Android Phones
}

\author{
Brenda Tamayo Oporto \\ System Engineering Professional Program \\ Católica Santa María University \\ Arequipa, Perú
}

\author{
Eveling Gloria Castro Gutierrez \\ CICA-UCSM \\ Arequipa, Perú
}

\begin{abstract}
Nowadays, the main problem we found in most smartphones is the poor battery life when using applications that make an intensive use of connectivity services. This becomes a serious problem in specific applications such as telemedicine; where services such as WiFi and $3 G$ connection are the largest consumers of energy, but are essential for the transfer of data required by these applications. This paper examines different energy consumption studies on mobile devices via WiFi and $3 G$. After this analysis, we propose and test a method for choosing the network with lower energy consumption based on the characteristics of the data transfer context that the application requires.
\end{abstract}

\section{Introduction}

Each day mobile devices show us more capabilities and services at our disposal; however, developments in battery capacity doesn't occur at the same rate [1] [2] [3] [4].Especially with connectivity services, which are the biggest battery consumers and the most used in applications that pursue user being always "connected". Thus the main problem we found in most smartphones is the poor battery life when using applications that make an intensive use of connectivity services.

The problem worsens in specific applications such as telemedicine, where the use of $\mathrm{WiFi}$ and $3 \mathrm{G}$ services, although they are the largest energy consumers, are essential to the operation of these applications, because they must have data transfer functions that goes from simple temperature data until tomography images; i.e. require a wide range of data [5].

One of the first steps for optimizing the use of energy is to know under what conditions the WiFi and $3 \mathrm{G}$ services are consuming battery. For this task, we analyzed several studies of energy consumption of networking services on mobile devices.

This analysis led to the design of a networking strategy choice. When the telemedicine application will perform a data transfer, the strategy chooses the network with the lower energy consumption. This choice is based on four transfer characteristics: connection status, signal strength, data size and transfer time.

In section III we present an analysis of previous works about energy consumption of interfaces WiFi and 3G. In section IV we proposed the design and implementation of the networking strategy choice. In section $\mathrm{V}$ we show our

We would like to acknowledge the support for this work from MicroData SRL, Fidecom and Catolica Santa Maria University. experiments with the method. Finally in section VI we discuss the conclusions and future work.

\section{Related Work}

Rahmati and Zhong analyzes the different energy consumptions for each phases of connection for the network interfaces [5]. The paper proposes to use the complementary strengths of each network to automatically select the most efficient according to background information of the network for Windows Mobile. They work in this problem from a statistical point of view.

Chong, Gaber, Krishnaswamyy and Loke proposes the development of a framework called CAS: Context Awareness in Sensing Enviroments, which objective is the energy conservation in sensors for wireless networks [6]. According to a set of rules the framework activates the most saving sensors. This work was made especially for the sensors of a PDA.

Zahid, Ali y Nassr develops and evaluates an Android service called ASPSS: Android Smart Power Save Service for the energy saving oriented to the user, tries to use the smartphone idle times to stop the technologies and applications with the most energy consumption according to the preferences of the user [3].

Kim, Min, Gupta, Mohapatra and Singh implements a system for Android smartphones that uses user motion information obtained through low battery sensors to outline the network information, and finally includes adaptive algorithms for WiFi detection that makes use of these profiles, in order to conserve battery power by enabling the detection phase when there is more possibilities that is a WiFi network available [7].

\section{Consumption Analysis wifi and 3g}

Compared to wired networks (Ethernet), wireless networking $\mathrm{WiFi}$ and $3 \mathrm{G}$ consume more energy. Based on minimum power for Ethernet, transmit data via WiFi incurs in an energy expenditure of $11.33 \%$ higher, while the use of $3 \mathrm{G}$ connection is $44 \%$ higher. Its expends are higher because the transmission medium is air, which has a higher attenuation condition, as well as other circumstances like multipath or interference [8]. However, the devices could not connect to the Internet without using them.

Works and experiments conducted suggest us that WiFi and $3 \mathrm{G}$, are the largest energy consumers of battery, and they also present various solutions to reduce this consumption [9] 
[10] [11]. Among the solutions they proposed one of the simplest ways to save energy is use the most saving network and turn off the rest, so that the application is in low energy states as much as possible [12] [13] [14]. But how do you know which network saves more energy? There are various issues that need to be analyzed, and are present below.

Although we tend to think that $3 \mathrm{G}$ consumes more than WiFi because its range of action covers large areas or its number of potential users [8]. Actually, the energy consume between WiFi and $3 \mathrm{G}$ is similar, but each one has its own energy characteristics at the different phases of connection: Establishing a connection, maintaining a connection, data transfer [11] [15] [16] [14]. In Rahmati, we can find a detailed study of the energy costs of $\mathrm{WiFi}$ and $3 \mathrm{G}$ connection [5]. Keep in mind if the connection is already turned on, it doesn't incur in an energy expense. This case can be seen in Table I on $3 \mathrm{G}$

Table 1. Network Energy Consumption [5]

\begin{tabular}{|c|c|c|}
\hline & $3 G$ & WiFi \\
\hline $\begin{array}{c}\text { Checking for } \\
\text { availability/establishing a } \\
\text { connection }\end{array}$ & 0 & $5 \mathrm{~J}$ \\
\hline $\begin{array}{c}\text { Maintaining a connection } \\
\text { Energy per MB transfer }\end{array}$ & $\begin{array}{c}\text { Upload: } 95-125 \mathrm{~J} \\
\text { Download: } 40-50 \mathrm{~J}\end{array}$ & $\begin{array}{c}\text { Upload: } 7-11 \mathrm{~J} \\
\text { Download: 5-7 J }\end{array}$ \\
\hline
\end{tabular}

Another aspect to consider in connection energy expenses is the vertical handoff, the energy cost of switching from one network to another, which must also be taken into account for the final calculation of the network energy cost. Petander indicates that the vertical handoff from $3 \mathrm{G}$ to $\mathrm{WiFi}$ consumes more energy than the $3 \mathrm{G}$ itself, and recommended switch to $\mathrm{WiFi}$ when the data size is greater than $0,12-0,9$ $\mathrm{Mb}$ [18].

Also other factors to measure the connection energy cost, are studied [5] [15] [16] [17] [19]. Transmit data consumes more energy that receive it [8].The data size to be transferred is a decisive factor, in $3 \mathrm{G}$ the larger the data size the greater the consumption we have, therefore studies show that is better using WiFi for large amount of data. In Kalic et al. they present mathematical models to estimate energy consumption according to the data size to transfer, these models were specially designed for Android devices [20].

Table 2. Energy Consumption Functions in respect to the amount of Transferred Data [17]

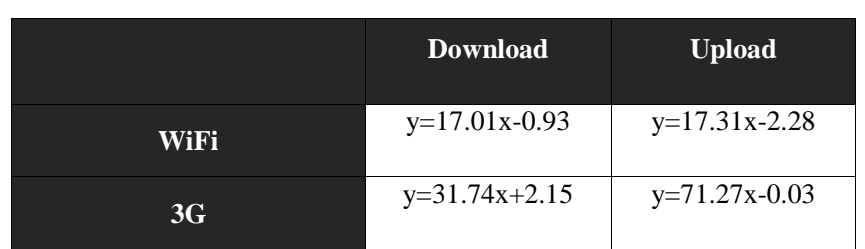

Together with the size data, the transfer time could be a factor too. As seen above in connection phases, while WiFi consumes more energy in maintaining the connection, save more energy in the data transfer, entirely contrary to $3 \mathrm{G}$; when the data size is small the time transfer cost is negligible. Kalic also presents a mathematical model in respect to the transfer time [20].

Table 3. Energy Consumption Functions in respect to the trasnfer Time [17]

\begin{tabular}{|c|c|c|}
\hline & Download & Upload \\
\hline WiFi & $\mathrm{y}=18.09 \mathrm{x}+0.17$ & $\mathrm{y}=21.24 \mathrm{x}-2.68$ \\
\hline $\mathbf{3 G}$ & $\mathrm{y}=20.59 \mathrm{x}-1.09$ & $\mathrm{y}=15.31 \mathrm{x}+2.67$ \\
\hline
\end{tabular}

Another factor is the signal strength, especially WiFi that has availability more varied than $3 \mathrm{G}$, the stronger the signal lower the energy cost. Even as the signal strength is decreasing the energy expense increases by a percentage.

To check the consumptions of $\mathrm{WiFi}$ and $3 \mathrm{G}$, tests were performed in a Smartphone Samsung Y Duos with Android 2.3. The Smartphone remained turn on for about an hour and a half, in daily use. The measurements were made using the application PowerTutor, this application generates an estimated energy consumption model [21].

Table 4. Energy Measurements Android Applications [Source: Own Elaboration]

\begin{tabular}{|c|c|c|}
\hline Applications & WiFi & 3G \\
\hline Media Server & $43,9 \mathrm{~J}$ & $17,6 \mathrm{~J}$ \\
\hline Internet & $18,1 \mathrm{~J}$ & $18,3 \mathrm{~J}$ \\
\hline Google Play Store & $9,7 \mathrm{~J}$ & $16,0 \mathrm{~J}$ \\
\hline Google+ & $4,4 \mathrm{~J}$ & $18,2 \mathrm{~J}$ \\
\hline Maps & $4,3 \mathrm{~J}$ & $17,7 \mathrm{~J}$ \\
\hline Youtube & $\mathbf{3 , 0} \mathrm{J}$ & $19,4 \mathrm{~J}$ \\
\hline Sincronización de Contactos & $1,4 \mathrm{~J}$ & $38,3 \mathrm{~J}$ \\
\hline Noticias \& Clima & $834,0 \mathrm{~mJ}$ & $9,2 \mathrm{~J}$ \\
\hline WhatsApp & $342,0 \mathrm{~mJ}$ & $30,4 \mathrm{~J}$ \\
\hline
\end{tabular}

As seen in Table IV the applications that transfer a large amount of data save more energy using $\mathrm{WiFi}$, although their connection remain connected for a longer time. And however there are cases, e.g. the application media server, in which despite of being active all the time, save more energy using $3 \mathrm{G}$, because de data size to be transfer was lower.

In the experiments, we didn't take into account the vertical handoff consumption, because the tests turn on one connection at a time. 


\section{Design and Implementation}

\subsection{Design}

In this paper we present the design of a method for choosing the network with lower energy consumption for an application. We develop this solution as an auxiliary service for a central telemedicine application with sending data functions.

The proposal divides basically in two modules, as it can be seen in Figure I, a most saving network choice module and a prediction module to improve the method performance.

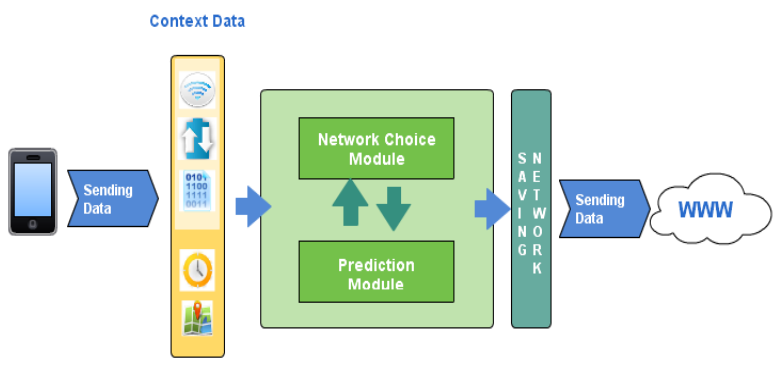

Figure 1. Overview of the Solution [Source: Own Elaboration]

\subsection{Network Choice Module}

This module is in charge of obtain which network interface, between $\mathrm{WiFi}$ and $3 \mathrm{G}$, is the one with lower energy consumption for sending data according to the connectivity context of the moment. This module is divided in 3 submodules that can be seen in Figure II.

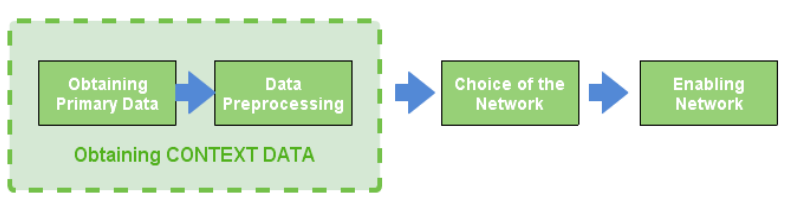

Figure 2. Network Choice Module [Source: Own Elaboration]

4.2.1. Obtaining Context Data: This module gets the enviroment information and the upcoming transfer information, the context. Some context data will be use for the algorithm choose network, that from this point on we will refer as connectivity context. The other part of the data will be used for the learning in the prediction module.

This is a list of the primary data necessary to define the context:

Location: Refers to the user location at the moment of sending the data and choice a network interface. We didn't use GPS location because is one of the largest battery consumers, so we use other locations strategies like Cell-ID and $\mathrm{WiFi}$.
Day of the week: refers to the day of the week at the moment of sending the data and choice a network interface. Time slot: refers to the time space of half an hour (for example 9:00- 9:30) in which the user sends data and the method choose a network interface.

Availability: refers if the network is available for the location, day of week and time slot given at the time of transfer. It is possible to connect to a network interface. For example there are locations where there is availability of a modem or access point to connect to $\mathrm{WiFi}$.

Connection Speed: refers to the speed of the network interface link, it's necessary for the algorithm choose network.

Packet size: refers to the size of the data for an upcoming transfer, it means the size of the data before sending it by Internet. It's necessary for the algorithm choose network.

Signal Strength: refers to the signal strength of the network interface, it's necessary for the algorithm choose network.

Based in some of these data we obtained two additional data:

Energy expense $x$ Time Transfer: Calculate based in the model of Kalic with the data size and the connection speed [20].

Energy expense $x$ Data Size: This model is estimated using primary data of the data size.

4.2.2. Choice of the Network: This submodule contains the algorithm for choose the most energy saving network interface. This choice is given according to the features of each connectivity context of the network in the given time. For the elaboration of this algorithm an analysis was made about the connectivity factors that impact in the energy consumption.

4.2.3. Enabling Network: This submodule executes the the election given by the previous submodule. Basically actives and connects the network interface chosen by the algorithm of choice, and off the other network.

\subsection{Algorithm Choose Network}

This algorithm bases its decision on the aspects seen in the consumption analysis of the previous section. This algorithm is divided into steps, each step represent an energy aspect to be evaluated.

In Figure 3, we show the pseudocode for this algorithm, and later we explain step by step, the aspects we are taking into account for the evaluation and later decision of the most saving network.

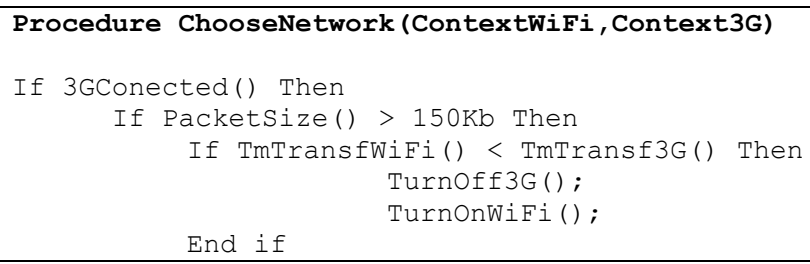




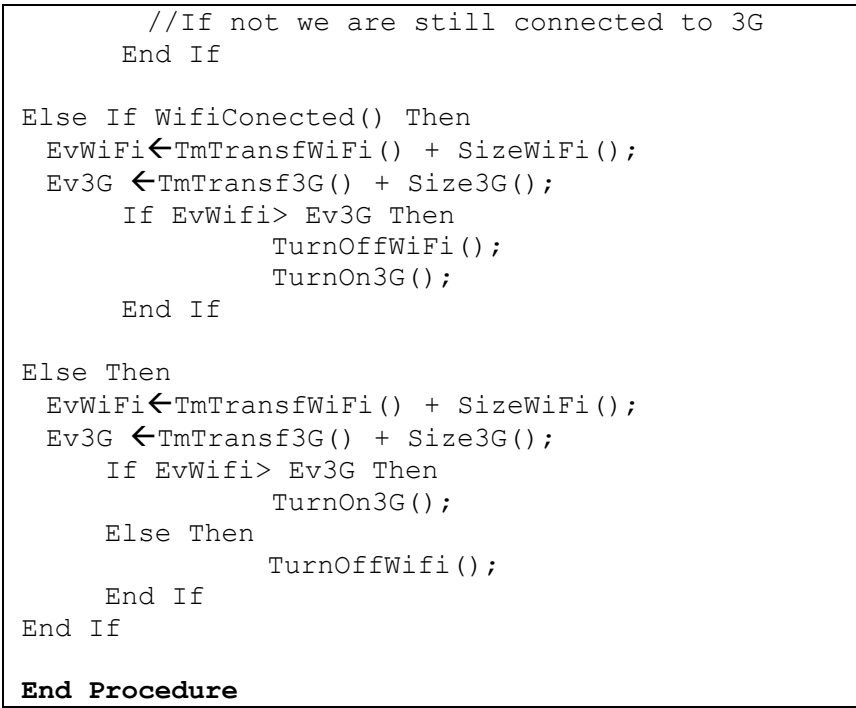

\section{Figure 3. Algorithm Choose Network [Source: Own} Elaboration]

4.3.1. Step 1: This network is active?: The scan and activation of a network involved an energy cost, which is why the first aspect to be taken into account is to check which of the two networks is active. If the WiFi is active, we will make an additional evaluation of signal strength because this is an important aspect in this interface.

4.3.2. Step 1.5 : How good is the signal strength?: If the WiFi signal is in a range of $75 \%-100 \%$ signal strength, it isn't an additional energy cost to the total [18]. Then one can proceed to evaluate de data size and the transfer time. Instead, if the signal strength is less than $75 \%$ is appropriate to add a penalty energy cost that is consistent with the decrease in the signal strength.

4.3.3. Step 2: Data Size Evaluation: WiFi saves more energy while the packet size is large. But according to what number we began to considerate that the size is large and we need to use WiFi? A measure obtained empirically and intuited by the work of Rahmati and Petander, brings us the approximate number of $150 \mathrm{~Kb}$, which also fit well with the energy cost of a vertical handoff from $3 \mathrm{G}$ to $\mathrm{WiFi}$ [5] [18].

In the case of $\mathrm{WiFi}$ and the additional penalties of signal strength, it's calculated with the formulas show in Table II.

4.3.4. Step 3: Transfer Time Evaluation: If the data size is small immediately choose $3 \mathrm{G}$ otherwise we have one more evaluation: the transfer time for large data. The transfer time can be calculated from the packet size and the speed of each connection. Once obtained this time is calculated with the energy cost of maintaining a connection. We compare the energy costs and choose the one that saves more energy.

\subsection{Prediction Module}

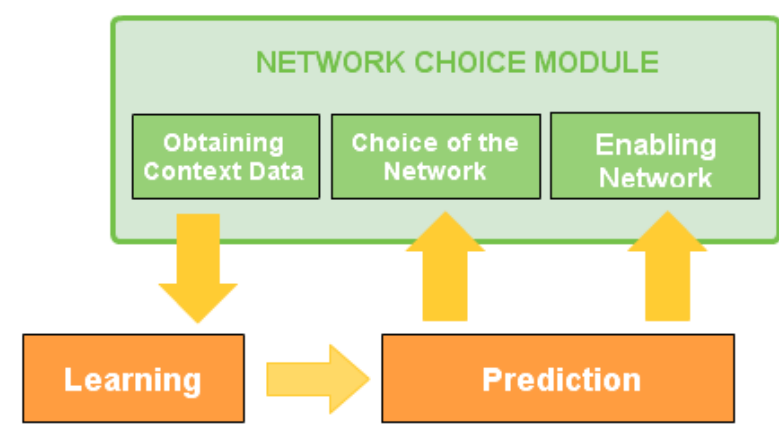

Figure 4. Prediction Module [Source: Own Elaboration]

According to a previous research, although we had a saving in the battery energy when using the algorithm of choice network, the algorithm incurred in an energy expenditure having to activate the two interfaces for getting the context data [22]. Thus this second module is devised to improve this weakness.

Being our solution developed at an application level we have limitations giving by Android system itself. Among them that in order to get the data from each network connectivity, this had to be active anyway. However, it was a chance to learn from previous choices given by the first module in a given context. Thus, if it has a context which already has made choices of network interface, we can learn from these choices and predict the most saving network without turning on the 2 interfaces, only by making use of previous cases. And that is precisely the function of the prediction module.

This module records the data context and the choice of network interface given by the algorithm for a period of time. With this information we generated a transition matrix for each context with records, the previous choices. We use Markov chains of Order one $\mathrm{O}(1)$ with stationary transition matrix.

As it can be seen in the Figure IV, this module has a strong connection with the network choice module. This module is divided into two other sub-modules:

4.4.1. Learning: This submodule records the network choices made for a determined context, and after a time of learning, a transition matrix is obtained for each context.

4.4.2. Prediction Network Interface: This submodule is executed whenever there is a transition matrix for the context. If there is no matrix or record of previous choices it proceeds to execute the algorithm. Once we have the transition matrix for a context we don't need to keep learning for this context.

So when we try sending data we consult if the context has a transition matrix, presenting two situations: 
- There is a matrix for the context: Based in this matrix we predict which network to choose according to previous experiences. Once the decision is made we use the enabling network submodule for turn on the interface.

- There is not matrix for the context: Which means we don't have previous experiences and is a new context. In this case we need to use the algorithm.

\subsection{Learning}

From the context data records the submodule generated the transition matrix. The context consists of the day of the week, time slot and location. In this context some data transfers are made, where previously the most saving network was chosen according to the connectivity context that was presented at that time. This context with the respective choice forms a training data record for the subsequent creation of a transition matrix.

So the training data has the following components: the day of the week, time slot, location, network choice at the moment and the previous network choice, as we work with Markov Chain of Order one $\mathrm{O}(1)$ is necessary the record of the previous choice for a determined context. With the actual choice and the previous choice we generated a transition matrix and generated a training data. In Figure $\mathrm{V}$ we can see an example of a training data with the transition matrix generated.

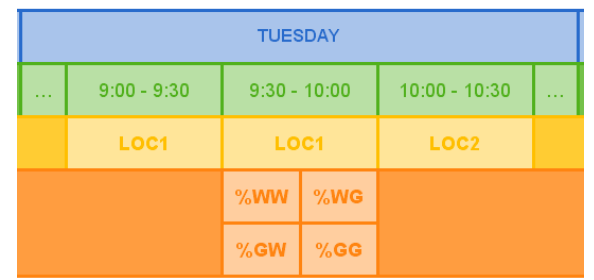

Figure 5. Example Training Data with transition matrix [Source: Own Elaboration]

This learning develops in a time given by the user, but as in any other learning with more data training we can have a better accuracy in our predictions. Once the user indicates the end of the learning data, we proceed to the automatic creation of the transition matrix. In Figure VI we can see the model of the matrix.

The transition matrix consists of 4 probabilities:

- WW: Probability to choose the WiFi network interface when the previous choice was WiFi.

- WG: Probability to choose the $3 \mathrm{G}$ network interface when the previous choice was WiFi.

- GW: Probability to choose the WiFi network interface when the previous choice was $3 \mathrm{G}$.

- GG: Probability to choose the 3G network interface when the previous choice was $3 \mathrm{G}$.

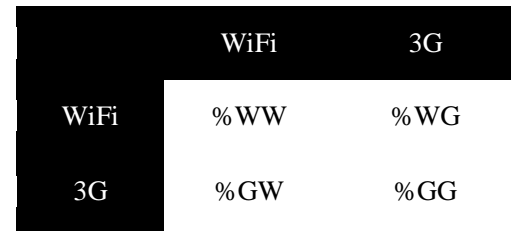

Figure 6. Model Transition Matrix [Source: Own
Elaboration]

\section{Experiments}

\subsection{Measurement Tool: PowerTutor}

PowerTutor is an application for Android phones that displays the power consumed by system components such as CPU, network interface, display, and GPS [21]. The application allows seeing the impact on power efficiency and battery life.

PowerTutor uses a power consumption model built by direct measurements during careful control of device power management states. This model generally provides power consumption estimates within $5 \%$ of actual values. It displays the power consumption history and also provides a text-file containing detailed results. One can use PowerTutor to monitor the power consumption of any application.

\subsection{Study Case}

The present work focuses in telemedicine applications which have almost indispensable functions for sending data, this is because medical data taken by a device must be verified by a specialist and should be store in a central database.

We develop a testing application that simulates the flow of data in a common application of telemedicine, as it can be seen in Figure VII, where data form a medical device is saved in a phone and the sent via Internet to a central server.

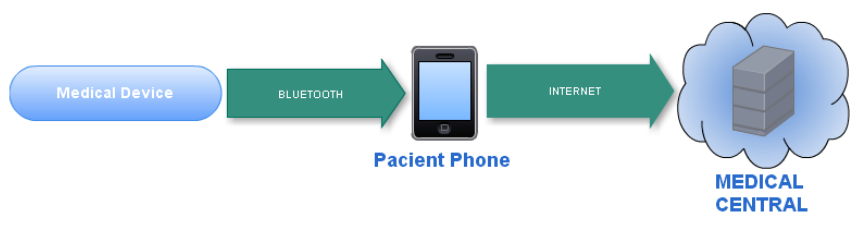

Figure 7. Flow data telemedicine application [Source: Own Elaboration]

Medical data are generated within the application, following the format of data: submission date, value of the data, unit, date, data type, sub data type, login, Medical Device ID, Mobile Device ID.

Usually such applications presents several scenarios under which it works, the most common are:

- Personal Use: A person has their own devices and makes use of them to send his/her data to the medical central. 
- Shared Device: A medical device is shared by multiple users to control and monitor the health.

- Doctor visits: Specialized medical staff recorded the control and monitoring of patients whom they make appointments, their work is sent as an entire block to the medical central.

To simulate these work scenarios we sent 3 sizes of data: sending a measurement, sending a series of measurements and sending a picture (since its size is large enough to represent a data set). In the case of simple measures are randomly generated. The mechanics of the application is to send some data every 10 minutes to the server.

\subsection{Initial Experiments}

The initial experiments are the tests made during the development of the solution to test it and see if there is actually a saving with the implemented solution.

We test the method in a smartphone Motorola XT914 Razr D1 with operating system Android 4.1 JellyBean, additionally it has the technical specifications of the Table V.

Table 5. technical specification - initial experiments [Source: Own Elaboration]

\begin{tabular}{|c|c|}
\hline 2G & $\begin{array}{c}\text { Bandas 850 / 900 / 1800 / 1900 MHz } \\
\text { Tecnología GSM / GPRS / EDGE }\end{array}$ \\
\cline { 2 - 2 } $3 \mathrm{G}$ & $\begin{array}{c}\text { Bandas 850 / 1900 / 2100 MHz } \\
\text { Tecnología UMTS/ HSDPA / HSUPA }\end{array}$ \\
\cline { 2 - 2 } Battery & $\begin{array}{c}\text { Duración 5.8 hrs } \\
\text { Modelo de Batería HW4X } \\
\text { Tiempo de Carga 4 hrs }\end{array}$ \\
Memory & Tipo de Batería Li-Ion de 1785 mAh \\
\hline Processor Speed & $\begin{array}{c}\text { Capacidad 4 GB } \\
\text { Memoria RAM 1 GB }\end{array}$ \\
Operating System & 1 GHz \\
& Android \\
& Versión 4.1 - JellyBean \\
\hline
\end{tabular}

As one can see e used a mid-range smartphone, with average characteristics. It is expected that if the solution works properly on this phone it will work equally good for phones with similar or even better characteristics.

5.3.1. Network Choice Module Test: The objective of this test was to verify that indeed the use of the network choice module saves a percentage of energy battery. This verification of the effectiveness of the algorithm is given but we returned to do the tests with the enhancements and changes made to the programming level algorithm for this work [22].

For the testing, three tests were performed, one using the energy saving solution and the other two using the WiFi network and the $3 \mathrm{G}$ network. For each test the battery was charged to $100 \%$ and the demo application was active for 5 hours. In this period we didn't use the smartphone for other activities.

To measure energy costs over this period the PowerTutor application was activated and the battery level decreases were seen in the detailed file that provides PowerTutor.

The results were compared and shown that effectively the method chooses the most saving network. By using $\mathrm{WiFi}$ the energy cost was $5358.08 \mathrm{~J}$ equivalents to $28 \%$ of spent battery and $3 \mathrm{G}$ use an energy cost of $6698.6 \mathrm{~J}$ equivalents to a $35 \%$. If we see the cost of the solution was $4405.04 \mathrm{~J}$ equivalents to $23 \%$. So an energy saving is achieved compared to using only the $\mathrm{WiFi}$ interface or $3 \mathrm{G}$ network. Savings of approximately $5 \%$ compared to $\mathrm{WiFi}$ and about $13 \%$ compared to $3 \mathrm{G}$.

\subsection{Prediction Module Test}

While the choice network module has an energy saving, according to our design we can have a better saving by using training data. As this is an experiment we used hard coded training data and thus also avoid the learning time because is not the main objective of this test.

For this test, there will be the same conditions than the previous tests: charge the phone to $100 \%$, enable the continuous transmission of data for 5 hours and use PowerTutor. Only that, this time, the prediction module was used.

In this test the energy cost was $4114.6 \mathrm{~J}$ about $21 \%$ of battery consumption. Compared with the results of the choice network module, applying a learning process can achieve better energy savings.

5.4.1. Users Experiments: In this section we present the results of the method validation given by expert users, people with some experience or knowledge in the problem area.

First we define an expert profile with the competences needed for this research. Which are the followings:

a) Attitude Review

b) Fairness Opinions

c) Possess knowledge of the Android operating system.

d) Possess basic knowledge of programming.

e) Possess knowledge of mobile network or WiFi and

3G data.

Also other conditions were also established, necessary to perform the validation.

- Count with a device with Android 2.3 or higher operating system.

- This device must be connected to the network interfaces: WiFi and $3 \mathrm{G}$.

- The person is capable to enable and disable network interfaces from the system settings.

\subsection{Energy Saving Test}

We realized the test for our solution on 10 different expert users. The mechanic of the test was the following. 
We install in their phones the measurement tool PowerTutor and the telemedicine application demo. This tests phase was divided in 3 parts:

- Day Zero: In this test the users had to have their battery at $100 \%$ of the capacity. And activate the continuous transmission of data during 5 hours; the schedule was election of each user it could be in the morning or in the afternoon. They had to continue their normal routine.

- Learning Time: In the beginning of this test, usually the next day after day zero, the user activates our saving energy method. In the GUI is only enabling a check. And in the same way that day zero they has to have the battery at $100 \%$ and activate the continuous transmission in the same schedule.

- Final Day: To avoid the users having to make additional settings, past the learning time automatically the learning stops and wait a moment because the transition matrices are created. Users should proceed in the same manner as the other days.

With this procedure we have information on the energy cost of using networks without the solution and after it is implemented.

\subsection{Devices Specifications}

In the Table VI we present the list of the used phones of each user and their most important characteristics which are the model and manufacturer, version of the operating system, battery capacity in milliampere-hours and the mobile operator, the provider for mobile internet.

Table 6. List of Device Specifications [Source: Own Elaboration]

\begin{tabular}{|c|c|c|c|c|}
\hline Usuario & $\begin{array}{c}\text { Modelo } \\
\text { Smartphone }\end{array}$ & $\begin{array}{c}\text { Versión S.O. } \\
\text { Android }\end{array}$ & $\begin{array}{c}\text { Capacidad } \\
\text { Batería } \\
\text { (mAh) }\end{array}$ & $\begin{array}{c}\text { Operador } \\
\text { móvil }\end{array}$ \\
\hline U01 & $\begin{array}{c}\text { MotoSmart } \\
\text { XT914 }\end{array}$ & 4.1 JellyBean & 1700 & Movistar \\
\hline U02 & $\begin{array}{c}\text { MotoSmart } \\
\text { XT389 }\end{array}$ & 2.3 Gingerbread & 1390 & Movistar \\
\hline U03 & $\begin{array}{c}\text { Samsung } \\
\text { Galaxy Y }\end{array}$ & 2.3 Gingerbread & 1200 & Movistar \\
\hline U05 & $\begin{array}{c}\text { Samsung } \\
\text { Galaxy Y } \\
\text { Duos }\end{array}$ & 2.3 Gingerbread & 1300 & Claro \\
\hline U06 & Airis TM400 & $\begin{array}{c}\text { 4.0.4 Ice } \\
\text { CreamSandwich }\end{array}$ & 1700 & Movistar \\
\hline U07 & $\begin{array}{c}\text { Samsung } \\
\text { Galaxy Y }\end{array}$ & 2.3 Gingerbread & 1200 & Claro \\
\hline U08 & $\begin{array}{c}\text { Samsung } \\
\text { Galaxy Ace }\end{array}$ & 2.3 Gingerbread & 1350 & Claro \\
\hline U09 & $\begin{array}{c}\text { Samsung } \\
\text { Galaxy S3 } \\
\text { mini }\end{array}$ & 4.1 JellyBean & 1500 & Movistar \\
\hline U010 & $\begin{array}{c}\text { Samsung } \\
\text { Galaxy S3 }\end{array}$ & 4.1 JellyBean & 2100 & Movistar \\
\hline
\end{tabular}

\subsection{Results}

The Table VII shows us the energy consumption of each device with and without the solution. These results are the measurements made by the application PowerTutor. This Table shows the results according to the Level of Energy Consumed $\mathrm{x}$ Time of Use in Joules.

Table 7. Energy Consumed Results [Source: Own Elaboration]

\begin{tabular}{|c|c|c|}
\hline \multirow{2}{*}{ User } & Day Zero & Final Day \\
\cline { 2 - 3 } & Energy consumed J & Energy consumed J \\
\hline U01 & 7982,2 & 6330,7 \\
\hline U02 & 2121,2 & 1811 \\
\hline U03 & 2922 & 1588,7 \\
\hline U04 & 879,5 & 1420 \\
\hline U05 & 6055,5 & 4679,25 \\
\hline U06 & 6881,3 & 5780,7 \\
\hline U07 & 2853 & 2678 \\
\hline U08 & 1894 & 1488 \\
\hline U09 & 2283 & 2595 \\
\hline U010 & 2284 & 1632,6 \\
\hline
\end{tabular}

The Table VIII shows us the percentage of battery spent of each device with and without the solution. These results were calculated with the measurements of the previous Table made by the application PowerTutor and the battery specification of each device. This Table shows the results according to the Percentage Battery Usage $\mathrm{x}$ Time of Use.

Table 8. Energy Consumed Results [Source: Own Elaboration]

\begin{tabular}{|c|c|c|}
\hline \multirow{2}{*}{ User } & Day Zero & $\begin{array}{c}\text { Final Day } \\
\text { U01 }\end{array}$ \\
\cline { 2 - 3 } & \% Battery Spent & \% Battery Spent \\
\hline U02 & $29 \%$ & $23 \%$ \\
\hline U03 & $34 \%$ & $28 \%$ \\
\hline U04 & $28 \%$ & $19 \%$ \\
\hline U05 & $13 \%$ & $21 \%$ \\
\hline U06 & $22 \%$ & $17 \%$ \\
\hline U07 & $25 \%$ & $21 \%$ \\
\hline U08 & $26 \%$ & $24 \%$ \\
\hline U09 & $28 \%$ & $22 \%$ \\
\hline U010 & $22 \%$ & $25 \%$ \\
\hline
\end{tabular}

To summarize we present the Table IX where one can see the measurements that have been made for both the "Level of Energy Consumed x Time of Use" as to "Percent Battery Usage By Time of Use". These two indicators show us the saving battery power of an Android device.

It is from this table where one can compare more clearly the results of the tests when the user did not have the solution and continued his/her routine, and when the user uses the solution on his/her smartphone. 
Table 9. Summarized Results [Source: Own Elaboration]

\begin{tabular}{|c|c|c|c|c|}
\hline \multirow[b]{2}{*}{ User } & \multicolumn{2}{|c|}{ Day Zero } & \multicolumn{2}{|c|}{ Final Day } \\
\hline & $\begin{array}{c}\text { Energy } \\
\text { consumed J }\end{array}$ & $\begin{array}{l}\text { \%Battery } \\
\text { Spent }\end{array}$ & $\begin{array}{c}\text { Energy } \\
\text { consumed J }\end{array}$ & $\begin{array}{c}\text { \%Battery } \\
\text { Spent }\end{array}$ \\
\hline U01 & 7982,2 & $29 \%$ & 6330,7 & $23 \%$ \\
\hline U02 & 2121,2 & $34 \%$ & 1811 & $28 \%$ \\
\hline U03 & 2922 & $28 \%$ & 1588,7 & $19 \%$ \\
\hline U04 & 879,5 & $13 \%$ & 1420 & $21 \%$ \\
\hline U05 & 6055,5 & $22 \%$ & 4679,25 & $17 \%$ \\
\hline U06 & 6881,3 & $25 \%$ & 5780,7 & $21 \%$ \\
\hline U07 & 2853 & $26 \%$ & 2678 & $24 \%$ \\
\hline U08 & 1894 & $28 \%$ & 1488 & $22 \%$ \\
\hline U09 & 2283 & $22 \%$ & 2595 & $25 \%$ \\
\hline U010 & 2284 & $26 \%$ & 1632,6 & $19 \%$ \\
\hline
\end{tabular}

As can be seen by comparing the percentages of spent battery from day zero and the last day, it can be seen that each user can save the phone battery using the method in a different level. All except the user U04 at first sight it seems that was not the case, but further review to detail was observed that on day zero the mobile application was not sending the amount of data that must be sent in time because at some point the user disabled the network connection, whereas the method automatically provided to activate an available network. Then, on day zero percentage is lower for this user because it had fewer data submissions.

\section{Conclusions}

It the initial experiments, the energy expenses in which incur the different network interfaces $\mathrm{WiFi}$ and $3 \mathrm{G}$ vary according to several factors such as data size, transfer time and energy costs of each interface. Thereby determining that each interface can be the most saving network according to the context at a given time.

The method for choosing a network presented in this paper allows battery saving using a set of rules considered by previous works and a later prediction, proposing the use of the network that has lower power consumption according to a preliminary evaluation and turn off the other networks.

This strategy allows the mobile to save battery according to a preliminary evaluation. But for this evaluation, we need to activate each network, which incurs in an additional cost. So for this weakness we design learning and prediction approach that avoids these unnecessary activations and improve the percentage of saving energy as it can be seen in the tests we realized in the present paper.

For future works we plan to add the $4 \mathrm{G}$ network interface in the solution, for this we need to do its own consumption analysis. Additional to this we plan to add a new evaluation feature also, that is the monetary cost of the use of mobile data.

\section{Acknowledgment}

This work was funded by the Research and Development Fund for Competitiveness and Enterprise Microdata SRL,
Peru, Contract No. 128-FINCyT-FIDECOM-PIPEI-2012 in collaboration with Health Center (Community Center UCSM) and the Interdisciplinary Center for Research and innovation at the Catolica Santa Maria University from Arequipa, Peru and Eveling Gloria Gutierrez Castro professor and researcher (CICA) at the Catolica Santa Maria University, with a Ph.D. in Computer Science at CONCYTEC-UNSA. Brenda Tamayo Oporto is part of the project team and studied at the Professional Program in Systems Engineering from the UCSM, and Robert E. Arisaca Mamani, is coordinator of the project, IEEE Member, Internet Society member and CEO of Microdata SRL, Arequipa - Peru.

\section{References}

[1] T. K. Kundu y K. Paul, «Improving Android performance and energy efficiency», en VLSI Design (VLSI Design), 2011 24th International Conference, 2011, pp. 256-261.

[2] B. K. Donohoo, C. Ohlsen, y S. Pasricha, «AURA: An application and user interaction aware middleware framework for energy optimization in mobile devices», en Computer Design (ICCD), 2011 IEEE 29th International Conference, 2011, pp. 168174.

[3] I. Zahid, M. A. Ali, y R. Nassr, «Android Smartphone: Battery saving service», en Research and Innovation in Information Systems (ICRIIS), 2011 International Conference, 2011, pp. 1-4.

[4] K. Nagata, S. Yamaguchi, y H. Ogawa, «A Power Saving Method with Consideration of Performance in Android Terminals», en Ubiquitous Intelligence \& Computing and 9th International Conference on Autonomic \& Trusted Computing (UIC/ATC), 2012 9th International Conference, 2012, pp. 578 - 585.

[5] A. Rahmati y L. Zhong, «Context-for-wireless: contextsensitive energy-efficient wireless data transfer», en Proceedings of the 5th international conference on Mobile systems, applications and services, 2007, pp. 165-178.

[6] S. K. Chong, M. M. Gaber, S. Krishnaswamy, y S. W. Loke, «Energy conservation in wireless sensor networks: a rule-based approach», Knowledge and information systems, vol. 28, n.o 3, pp. 579-614, 2011.

[7] K. H. Kim, A. W. Min, D. Gupta, P. Mohapatra, y J. P. Singh, «Improving energy efficiency of wi-fi sensing on smartphones», en INFOCOM, 2011 Proceedings IEEE, 2011, pp. 2930-2938.

[8] G. De las Nieves Jiménez, «Ahorro energético en la transmisión de datos a sistemas móviles», Universidad Carlos III de Madrid Escuela Politécnica Superior, 2012.

[9] Y. Wang, J. Lin, M. Annavaram, Q. A. Jacobson, J. Hong, B. Krishnamachari, y N. Sadeh, «A framework of energy efficient mobile sensing for automatic user state recognition», en Proceedings of the 7th international conference on Mobile systems, applications, and services, 2009, pp. 179-192.

[10] J. Sharkey, «Coding for life-battery life, that is», en Google IO Developer Conference, 2009. 
[11] A. Gupta y P. Mohapatra, «Energy consumption and conservation in wifi based phones: A measurement-based study», en Sensor, Mesh and Ad Hoc Communications and Networks, 2007. SECON'07. 4th Annual IEEE Communications Society Conference on, 2007, pp. 122-131.

[12] T. Pering, Y. Agarwal, R. Gupta, y R. Want, «Coolspots: Reducing the power consumption of wireless mobile devices with multiple radio interfaces», en Proceedings of the 4th international conference on Mobile systems, applications and services, 2006, pp. 220-232.

[13] M. A. Viredaz, L. S. Brakmo, y W. R. Hamburgen, «Energy management on handheld devices», Queue, vol. 1, n.o 7, p. 44, 2003.

[14] S. K. Datta, C. Bonnet, y N. Nikaein, «Android power management: Current and future trends», en Enabling Technologies for Smartphone and Internet of Things (ETSIoT), 2012 First IEEE Workshop on, 2012, pp. 48-53.

[15] K. Lin, A. Kansal, D. Lymberopoulos, y F. Zhao, «Energyaccuracy aware localization for mobile devices», en Proceedings of 8th International Conference on Mobile Systems, Applications, and Services (MobiSys' 10), 2010.

[16] A. J. Pyles, Z. Ren, G. Zhou, y X. Liu, «SiFi: exploiting VoIP silence for WiFi energy savings insmart phones», en Proceedings of the 13th international conference on Ubiquitous computing, 2011, pp. 325-334.

[17] M. R. Ra, J. Paek, A. B. Sharma, R. Govindan, M. H. Krieger, y M. J. Neely, «Energy-delay tradeoffs in smartphone applications», en Proceedings of the 8th international conference on Mobile systems, applications, and services, 2010, pp. 255-270.

[18] H. Petander, «Energy-aware network selection using traffic estimation», en Proceedings of the 1st ACM workshop on Mobile internet through cellular networks, 2009, pp. 55-60.

[19] N. Balasubramanian, A. Balasubramanian, y A. Venkataramani, «Energy consumption in mobile phones: a measurement study and implications for network applications», en Proceedings of the 9th ACM SIGCOMM conference on Internet measurement conference, 2009, pp. 280-293.

[20] G. Kalic, I. Bojic, y M. Kusek, «Energy consumption in android phones when using wireless communication technologies», en MIPRO, 2012 Proceedings of the 35th International Convention, 2012, pp. 754-759.

[21] L. Zhang, B. Tiwana, Z. Qian, Z. Wang, R. P. Dick, Z. M. Mao, y L. Yang, «Accurate online power estimation and automatic battery behavior based power model generation for smartphones», en Proceedings of the eighth IEEE/ACM/IFIP international conference on Hardware/software codesign and system synthesis, 2010, pp. 105-114.

[22] B. Tamayo Oporto y E. Castro Gutierrez, «Networking Strategy Choice based in data transfer in Android Devices», en Proceedings International Conference on Information Society, Toronto, Canada, 2013, p. 4. 